\title{
Posterior chest wall reconstruction with a free anterolateral thigh flap
}

\author{
Raymond W. M. Ng, MD, FRCSE, FACS, George K. H. Li, MD, FRCSE, Jimmy Y. W. \\ Chan, MD, MRCSE, and Josephine Y. W. Mak, MD, MRCSE, Hong Kong, China
}

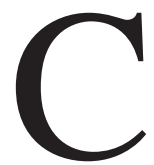

hest wall defects can be traumatic, infectious, or neoplastic in origin. ${ }^{1}$ Sometimes their reconstruction can be difficult, depending on the complexity of tissue required. ${ }^{2}$ Primary closure is not always possible after ablative surgery. Similarly, prior treatment with irradiation renders the remaining tissue unfit for skin grafting. On the other hand, local flaps and regional flaps might not be available or might be of inadequate size to cover the defect. Under these conditions, free tissue transferal is the best reconstructive option. We report the successful reconstruction of a wide posterior chest wall defect using a free anterolateral thigh myocutaneous flap.

\section{Clinical Summary}

A 69-year-old man had a history of excision of a cutaneous high-grade sarcoma of his left scapula region 5 years previously. The skin defect overlying the infraspinatus was skin grafted, and postoperative irradiation was administered. He presented again with a 2-month history of a progressively enlarging mass, which measured $6 \times 6 \mathrm{~cm}$, on the inferior aspect of the previous operation site. Tru-cut biopsy confirmed the recurrence of sarcoma.

Resection of the tumor and flap elevation was performed simultaneously by placing the patient in a lateral position and the left hip slightly abducted so that the posterior chest and the left thigh were exposed altogether. The tumor was found to be limited to the soft tissue of the chest wall, and there was no invasion of the underlying rib cage. Wide local excision with a $3-\mathrm{cm}$ radial margin was performed. The latissimus dorsi and serratus anterior muscles were resected because of tumor involvement. Moreover, the lower half of the adjacent scapula was also removed. After the tumor extirpation, after-loading brachytherapy tubes were inserted for postoperative interstitial irradiation. The resultant chest wall defect, measuring $10 \times 16 \mathrm{~cm}$, and the exposed fourth to seventh ribs needed to be covered (Figure 1).

From the Division of Plastic and Reconstructive Surgery, Department of Surgery, University of Hong Kong Medical Centre, Queen Mary Hospital, Hong Kong, China.

Received for publication April 8, 2007; accepted for publication April 26, 2007.

Address for reprints: Raymond W. M. Ng, MD, FRCSE, FACS, Division of Plastic and Reconstructive Surgery, Department of Surgery, University of Hong Kong Medical Centre, Queen Mary Hospital, 102 Pokfulam Rd, Hong Kong SAR, China (E-mail: ngwmr@hkucc.hku.hk).

J Thorac Cardiovasc Surg 2007;134:537-8

$0022-5223 / \$ 32.00$

Copyright () 2007 by The American Association for Thoracic Surgery doi:10.1016/j.jtcvs.2007.04.026
By using the same position, an anterolateral thigh myocutaneous flap with a skin island of $13 \times 18 \mathrm{~cm}$ was raised from the left thigh. Two musculocutaneous perforators detected by using the hand-held Doppler de-

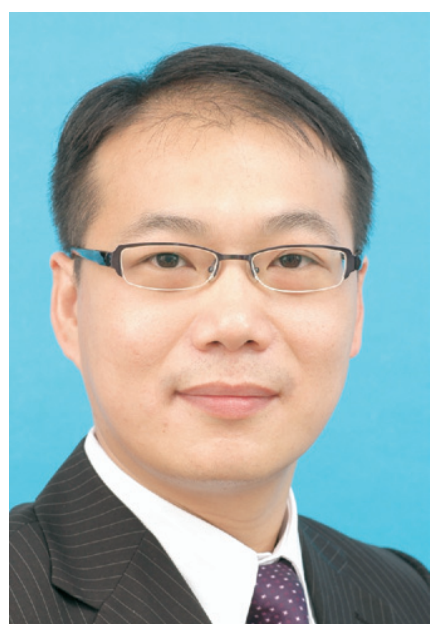

Dr Ng vice were included in the flap dissection. The flap was transposed to cover the defect and the brachytherapy tubes. Flap circulation was re-established with microvascular anastomosis to the thoracodorsal vessels (Figure 2). The thigh donor site was grafted with a split-thickness meshed skin graft harvested from the patient's hip. The wound remained healthy without infection, flap necrosis, or dehiscence. At 8 weeks' follow-up, the brachytherapy tubes were removed after completion of the irradiation, and there was no functional disability to the patient's lower limb.

\section{Discussion}

Chest wall reconstruction after major tumor resection remains a challenging problem for the surgeon. Local tissue might not be adequate for repair in the presence of complex defects, such as wide, full-thickness chest wall defects. ${ }^{2}$ Prior treatments, such as irradiation, can also leave the local tissue unsuitable or unavailable for reconstruction. Regional flaps transposing tissue outside the chest wall territory are an alternate choice. Different regional flaps have been proposed for the anterior or anterolateral aspect of the chest wall reconstruction. Among these, the latissimus dorsi musculocutaneous flap and the rectus abdominis musculocutaneous flap are common examples. ${ }^{3}$ Nevertheless, there are occasions when both the local tissue and regional flap are not feasible and free tissue transfer offers the only possible option. ${ }^{4}$

We reported a case of a posterior chest wall acquired defect after tumor resection requiring reconstruction. Technically, it is much more difficult to manage a posterior chest wall defect because many common regional flaps cannot reach this site. Also, the flap harvesting and insetting can seldom be performed without changing the patient's position after resection of the tumor.

The anterolateral thigh flap located on the anterior and outer aspect of the thigh is a versatile and reliable flap based on the descending branch of the lateral circumflex femoral artery. ${ }^{5}$ It has a long pedicle and sizeable vessels for anastomosis. The flap dissection is relatively straightforward. With the patient placed in a lateral position and the hip abducted, both tumor resection and 

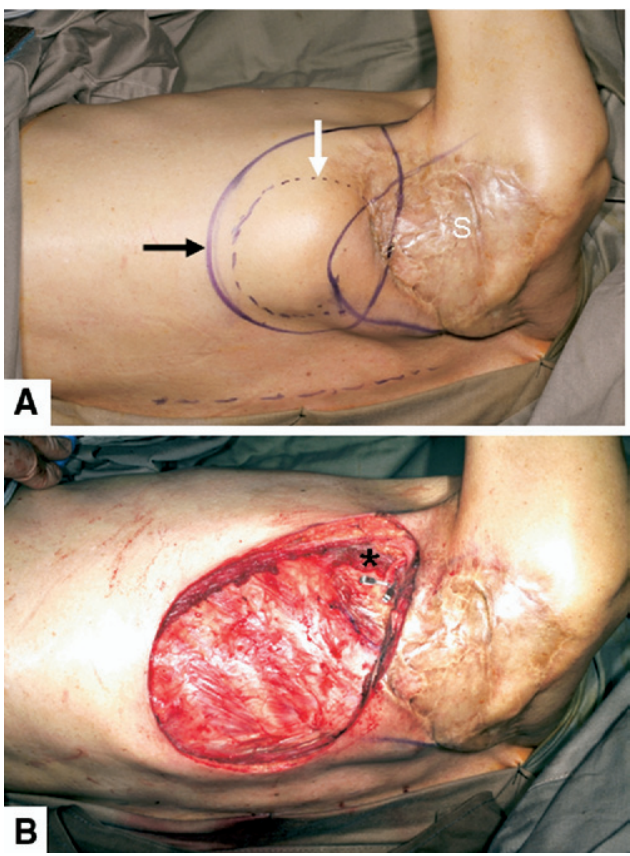

Figure 1. A, The dotted line (white arrow) outlined the size of the recurrent soft tissue sarcoma of the posterior chest wall on the left side. The solid line (black arrow) represented the planned incision. The scapula $(S)$ had skin graft covering the infraspinatus muscle after the previous operation. $B$, The chest wall defect created after wide local resection and the fourth to seventh ribs were exposed. The inferior portion of the scapula was resected. The thoracodorsal artery and vein $(*)$ were preserved as the recipient vessel.

flap elevation can be performed in one setting, thus alleviating the change of position during the operation. In addition, a large piece of skin island can be designed, and the donor site morbidity is minimal, even when skin grafting is necessary, as in this case. In fact, for a smaller flap dimension, the donor site can always be closed primarily. The muscle component of the flap acts as bulk and has the added advantage of filling potential space, contouring the defect, and keeping the brachytherapy tubes in place. We recommend using the anterolateral thigh flap as the flap of choice if free tissue reconstruction of the chest wall is indicated.

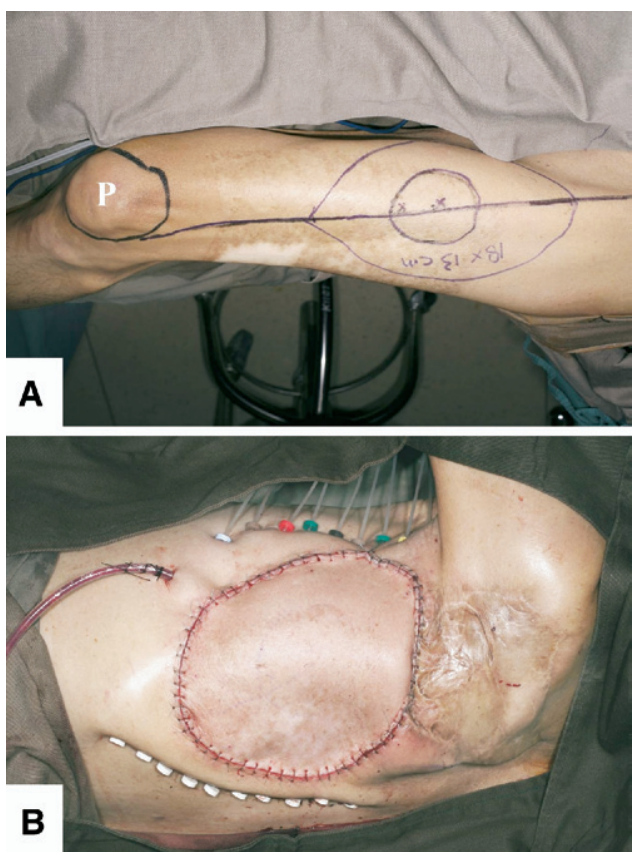

Figure 2. A, An anterolateral thigh flap outlined on the left thigh. It was designed on a line joining the lateral patella $(P)$ and the anterior superior iliac spine, where the perforators $(x)$ of the flap were identified preoperatively by using the hand-held Doppler device. B, The flap was inset to cover the chest wall defect and the brachytherapy tubes.

\section{References}

1. Larson DL, McMurtrey MJ. Musculocutaneous flap reconstruction of chest-wall defects: an experience with 50 patients. Plast Reconstr Surg. 1984;73:734-40.

2. Akan M, Eker Ulucay G, Kargi B, Yildirim S, Akoz T. Combined reconstruction of complex defects of the chest wall. Scand J Plast Reconstr Surg Hand Surg. 2006;40:93-100.

3. Mathes SJ. Chest wall reconstruction. Clin Plast Surg. 1995;22:187-98.

4. Tukiainen E, Popov P, Asko-Seljavaara S. Microvascular reconstructions of full-thickness oncological chest wall defects. Ann Surg. 2003; 238:794-802.

5. Gedebou TM, Wei FC, Lin CH. Clinical experience of 1284 free anterolateral thigh flaps. Handchir Mikrochir Plast Chir. 2002;34:239-44. 